\title{
Sustainable and green synthesis of stanol esters from oil wastes
}

María Molina-Gutiérrez, Leonor Rodríguez-Sánchez, Carmen Doñoro, M. Jesús Martínez*, and Alicia Prieto*

Centro de Investigaciones Biológicas Margarita Salas, Consejo Superior de Investigaciones Científicas, Ramiro de Maeztu 9, 28040 Madrid, Spain

E-mail: $\quad$ mariamg@cib.csic.es; leonor@cib.csic.es; carmendova@cib.csic.es; mjmartinez@cib.csic.es; aliprieto@cib.csic.es

*Correspondence: Centro de Investigaciones Biológicas Margarita Salas, Department of Microbial and Plant Biotechnology, CSIC, Ramiro de Maeztu 9, E-28040 Madrid, Spain. Tel.: +34 918373112; fax: +34 91536043. E-mail address: aliprieto@cib.csic.es 
ABSTRACT. The recombinant lipase of Ophiostoma piceae (OPEr) is characterized for

2 its prominent sterol esterase activity. The protein was immobilized on magnetic

3 nanoparticles, giving four enzyme variants that have been tested in solvent-free

4 transesterification of methyl oleate and sitostanol. The yields of stanol esters reached

$585 \%$, and the catalysts can be reused. Stanol esters were also obtained in a two-step

6 cascade reaction; a mixture of fatty acid methyl esters was enzymatically synthetized

7 from cooking oil wastes and then used for stanols transesterification. An $85 \%$ conversion

8 was achieved in $2 \mathrm{~h}$ from the second cycle onwards, maintaining the activity over 5 cycles.

9 The biocatalysts can be safely used since they don't release toxic compounds for HeLa

10 and A549 cell lines. These procedures comply with the principles of green chemistry and

11 contribute to the sustainable production of these nutraceuticals from secondary raw

12 materials, like the lipid fraction from industrial or agricultural residues.

13

14 Keywords: biocatalysis, enzymatic transesterification, phytosterols, FAMEs, sustainability, 15 wastes, OPEr. 
Sterols are a family of compounds that perform relevant structural and physiological functions in eukaryotes as components of the cell membranes of animals, plants, and

19 fungi. Chemically, sterols are lipids that have a bulky, hydrophobic ring with a $\beta$-3hydroxyl group, which confers a slight polarity to the molecule, and a small aliphatic

21 chain. This structural similarity is at the basis of the use of phytosterols to reduce cholesterol levels, as they compete with cholesterol absorption in the gut in animals and humans. ${ }^{1}$ Stanols are the saturated forms of sterols, and appear to be more efficient cholesterol-lowering agents because they are more hydrophobic, have less micellar solubility and therefore their intestinal absorption is lower. ${ }^{2,3}$ While the use of free sterols and stanols as dietary supplements is limited by their low solubility, their esters have properties comparable to edible fats and oils, which facilitates their incorporation into fatty foods, and are more bioavailable. ${ }^{4}$

The industrial production of these nutraceutical esters is usually done by chemical methods using acid or basic catalysts, and the development of competitive enzymatic technologies would be welcome. A small group of lipases and sterol esterases have shown their ability to catalyze the esterification/transesterification of these hydrophobic and bulky substrates in mild reaction conditions, without generating unwanted by-products. ${ }^{3,5-12}$ The use of immobilized enzymes may help upscaling the process, improving the catalyst stability, enabling its recovery and re-use, and reducing costs. Within the food, cosmetics and pharmaceutical sectors, where the final product delivered to the consumer must be free of residual enzyme, ${ }^{13}$ only processes based on the use of immobilized enzymes, attached or embedded in an insoluble carrier, are 
gaining industrial importance. ${ }^{14}$ Many types of scaffolds, from biopolymers to inorganic compounds, have been used to immobilize lipases, ${ }^{3}$ and magnetic nanoparticles have

41 become very popular carriers for their excellent properties. One of them is superparamagnetism, which allows easy and virtually immediate separation of the catalyst under external magnetic fields. ${ }^{15,16}$

The commercial lipase CRL from Candida rugosa is probably the best known biocatalyst applied for the synthesis of phytosterol esters and has been tested under many experimental conditions. ${ }^{3}$ However, the recombinant form of a versatile lipase produced naturally by the fungus Ophiostoma piceae (OPEr) shows outstanding activity against phytosterols and their esters. ${ }^{17}$ We have demonstrated that OPEr was much more efficient in the synthesis of stanol esters by direct esterification or transesterification, and under extremely mild conditions, than $\mathrm{CRL},{ }^{4}$ the commercial lipases Cal A and Cal B from Candida antarctica, ${ }^{18}$ and other recombinant lipases produced in our laboratory. ${ }^{19,20}$ We recently immobilized and tested OPEr for direct esterification of volatile fatty acids with good results, ${ }^{21}$ and an additional immobilized

54 variant of OPEr has been prepared and tested in this work. Here, we address the synthesis of stanol esters in green reactions, at room temperature and without the

56 addition of organic solvents, catalyzed by several immobilized forms of OPEr. We have

57 also designed and tested a cascade reaction to produce these nutraceuticals using vegetable oil residues as fatty acid donors. 
Materials. $\quad \beta$-sitostanol, $\quad p$-nitrophenyl butyrate $\quad(p N P B)$,

aminopropyl)triethoxysilane 99\% (APTS), methyl oleate, MTT (3-(4,5-dimethylthiazol-2-

yl)-2,5-diphenyltetrazolium bromide), colchicine, SDS and dimethylformamide were from Sigma-Aldrich (St. Louis, MO, USA). Other chemicals and solvents of the purest available grade were provided by Merck (Darmstadt, Germany).

Strains, culture conditions, and preparation of enzyme crudes. Pichia pastoris

GS115 strain containing the ope gene was maintained and cultivated to produce the versatile lipase OPEr as previously reported. ${ }^{20}$ The cultures were then centrifuged $\left(27,666 \mathrm{~g}, 4{ }^{\circ} \mathrm{C}\right)$ and fungal biomass discarded. Supernatants were concentrated by ultrafiltration in an YM3 Amicon device (Merck Millipore, Darmstadt, Germany) with a 50-kDa membrane. The crude extract obtained was used without further purification.

Evaluation of enzyme activity. The standard assay to determine the activity of the catalyst was carried out monitoring the release of $p$-nitrophenol from hydrolysis of 1.5 $\mathrm{mM}$ pNPB in $20 \mathrm{mM}$ Tris- $\mathrm{HCl} \mathrm{pH} 7.0$ at room temperature at $410 \mathrm{~nm}$ using a Shimadzu UV-160A spectrophotometer. One unit of activity $(1 \mathrm{U})$ is defined as the amount of enzyme used to release $1 \mu \mathrm{mol}$ of $p$-nitrophenol $\left(\varepsilon_{410}=15,200 \mathrm{M}^{-1} \mathrm{~cm}^{-1}\right)$ per minute under the defined conditions.

Immobilization of OPEr. Magnetic nanoparticles (Iolitec, GmbH Heilbronn, Germany) were silanized and functionalized with $\mathrm{NH}_{2}$ groups as described. ${ }^{21}$ Concentrated extracts containing OPEr were immobilized on amino-functionalized 81 magnetic nanoparticles (AMNP) by four procedures. The enzyme was non-covalently 82 bound by hydrophobic interaction (SiMAG-Octyl-OPEr), and covalently to 83 glutaraldehyde-activated AMNPs (AMNPs-GA-OPEr) and as magnetic cross-linked 
enzyme aggregates (mCLEAs-OPEr), as previously reported. ${ }^{21}$ The fourth immobilization procedure takes advantage of the fact that OPEr is glycosylated, and involved oxidation of the glycidic chains of OPEr with $10 \mathrm{mM} \mathrm{NaIO}_{4}$ in $5 \mathrm{mM}$ Tris- $\mathrm{HCl} \mathrm{pH} 7$ at $4{ }^{\circ} \mathrm{C}$ for $3 \mathrm{~h}$. After treatment, the samples were dialyzed against $20 \mathrm{mM}$ Tris- $\mathrm{HCl} \mathrm{pH} 7$ in a 30-kDa cut off centrifuge filter (Amicon Ultra-15, Millipore). The enzyme solution was mixed with AMNPs in $100 \mathrm{mM}$ Tris- $\mathrm{HCl}$ pH 8 with $150 \mathrm{mM}$ trimethyl amino borane, stirring at 100 $\mathrm{rpm}$ and $28^{\circ} \mathrm{C}$ for $150 \mathrm{~min}$. The AMNPs with the bound protein were captured with a magnet, treated with $\mathrm{NaBH}_{4}(1 \mathrm{~h})$ and washed with $100 \mathrm{mM}$ and $20 \mathrm{mM}$ Tris- $\mathrm{HCl} \mathrm{pH} \mathrm{7,}$ and the final catalyst was named AMNPs-CH-OPEr.

The activity provided, the immobilized activity (difference between starting activity and residual activity measured in the supernatant after immobilization) and the activity of the immobilized catalysts (observed activity), were determined using $p N P B$ as substrate. The immobilization parameters were calculated according to Sheldon and van Pelt: ${ }^{13}$

Yield $(\%)=($ immobilized activity/starting activity $) \times 100$

Efficiency $(\%)=($ observed activity/immobilized activity) $\times 100$

Activity recovery $(\%)=$ (observed activity/starting activity) $\times 100$

Enzymatic synthesis of stanol esters by solvent-free transesterification. A 80-mM solution of stanols in $99 \%$ methyl oleate was first prepared and warmed ( $50 \stackrel{\circ}{\circ}$ ) for a few minutes to ensure that stanols were completely dissolved before pipetting. Then, $500 \mu \mathrm{L}$ of the solution were placed in a vial, adding cholest-4-en-3-one (internal standard for GC quantification), $20 \%$ of water and $35 \mathrm{U}$ of OPEr, maintaining the reaction at $25^{\circ} \mathrm{C}$ for up to $15 \mathrm{~h}$ with $100 \mathrm{rpm}$ rotational mixing (Multi Bio RS-24, 
107 Biosan). No co-solvent was added since methyl oleate acted also as the reaction

108 solvent. After each reaction cycle the biocatalysts were washed with isooctane and 20

$109 \mathrm{mM}$ Tris- $\mathrm{HCl}$ buffer $\mathrm{pH} 7$ and reused under the same conditions. The experiments were

110 performed in duplicate, monitoring the reaction by gas chromatography (GC) as

111 previously reported. ${ }^{4}$ Since not commercial standards of the synthetized esters were

112 available, the esterification yields were calculated from the amount of residual free

113 stanols according to the formula:

where $[\text { stanol }]_{i}$ and $[\text { stanol }]_{f}$ are the initial and final concentration of stanols.

$117500 \mu \mathrm{L}$ of wastes of cooking olive oil was used to obtain a mixture of fatty acid methyl

118 esters (FAMEs) by solvent-free methanolysis $\left(25^{\circ} \mathrm{C}, 100 \mathrm{rpm}\right.$, molar ratio oil:methanol

119 1:4) using AMNP-CH-OPEr (70 U) as the catalyst. Once the reaction was completed, the

120 liquid part of the reaction mixture was analyzed by gas chromatography/mass

121 spectrometry (GC/MS) to confirm the disappearance of the peaks from triglycerides and

122 the appearance of others from the FAMEs. Then, it was used as reaction solvent and

123 source of acyl donors to synthetize stanol esters. Transesterification with AMNP-CH-

124 OPEr was accomplished as indicated in the previous section, except for the acyl donor.

125 The reaction mixture containing the stanol esters was analyzed by gas chromatography

$126(\mathrm{GC})$ as reported. ${ }^{4}$

127 GC/MS analysis. The analyses were performed in an Agilent instrument equipped

128 with a 7890A GC, a 5975C quadrupolar mass detector, and a DB5-HT column (30 m, 0.25

$129 \mathrm{~mm}$ internal diameter, $0.1 \mu \mathrm{m}$ film thickness). To analyze the commercial sample of $\beta$ - 
130 sitostanol, the temperature program was: $180^{\circ} \mathrm{C}$ to $205^{\circ} \mathrm{C}\left(\right.$ ramp rate $\left.3^{\circ} \mathrm{C} / \mathrm{min}\right)$, then

131 to $220^{\circ} \mathrm{C}\left(10^{\circ} \mathrm{C} / \mathrm{min}\right)$ maintaining this temperature for $5 \mathrm{~min}$, and finally from $220^{\circ} \mathrm{C}$ to

$132400{ }^{\circ} \mathrm{C}$, keeping the final temperature for $5 \mathrm{~min}$. Commercial methyl oleate and the

133 mixture of FAMEs enzymatically synthetized in the laboratory were analyzed using a

134 program that started at $80{ }^{\circ} \mathrm{C}(4 \mathrm{~min})$ and then raised to $300{ }^{\circ} \mathrm{C}\left(20{ }^{\circ} \mathrm{C} / \mathrm{min}\right)$. The

135 compounds detected were identified using commercial standards, analyzed under

136 identical conditions to the samples or through their mass spectra using the NIST 2011

137 library and the ChemStation software (Agilent, Santa Clara, CA, USA).

138 In vitro cytotoxicity assay. The migration of potentially toxic compounds from the

139 immobilized biocatalysts was also evaluated. Stock suspensions of each biocatalyst in

140 sterile PBS pH 7.4 (700 mg/mL for AMNP-CH-OPEr, mCLEAs-OPEr and SiMAG-Octyl-OPEr

141 and $1250 \mathrm{mg} / \mathrm{mL}$ for AMNP-GA-OPEr) were maintained in agitation for $24 \mathrm{~h}$. The

142 supernatants were recovered and filtered $(0.22 \mu \mathrm{m})$ before being added to the cell

143 cultures in the appropriate amounts. Cytotoxicity was tested exposing human cell lines

144 HeLa and A549 to these supernatants.

145 Human HeLa cells from cervix carcinoma were continuously maintained in DMEM

146 enriched with high glucose and pyruvate. Non-small cell lung carcinoma A549 cells were

147 cultured in RPMI-1640 with L-glutamine at $37{ }^{\circ} \mathrm{C}$ in $5 \% \mathrm{CO}_{2}$. Both media were 148 supplemented with $10 \%$ fetal bovine serum, $10 \mathrm{U} / \mathrm{mL}$ penicillin, and $10 \mu \mathrm{g} / \mathrm{mL}$

149 streptomycin. Cells were seeded in a 96 -well plate at a density of 120,000 cells $/ \mathrm{mL}$ for

150 HeLa and 160,000 cells/mL for A549 cells. Then, $80 \mu \mathrm{L}$ were added per well and cultured

151 in $5 \% \mathrm{CO}_{2}$ at $37^{\circ} \mathrm{C}$ for $24 \mathrm{~h}$. Cells were then exposed to $20 \mu \mathrm{L}$ serial dilutions of the four

152 stock solutions of the biocatalysts for $48 \mathrm{~h}$. The maximum concentrations tested 
153 corresponded to suspensions with $140 \mathrm{mg} / \mathrm{mL}$ of each nanobiocatalyst $(250 \mathrm{mg} / \mathrm{mL}$ for

154 AMNP-GA-OPEr). Viable cells were determined in a MTT assay ${ }^{22}$ with some 155 modifications Briefly, $20 \mu \mathrm{L}$ of $2.5 \mathrm{mg} / \mathrm{mL}$ MTT was added to each well, incubated for 4 $156 \mathrm{~h}$ at $37{ }^{\circ} \mathrm{C}$, and then treated with $0.1 \mathrm{~mL}$ of a solution containing $10 \%$ SDS and $45 \%$

157 dimethylformamide $\mathrm{pH} 5.5$ and incubated overnight at $37^{\circ} \mathrm{C}$ to solubilize the blue 158 formazan precipitate. The absorbance at 595/690 $\mathrm{nm}$ was measured in an automated 159 Multiscan microplate reader (Spectra Max Plus 384, Molecular Devices, San Jose, CA, 160 USA). Controls containing medium without cells were used as blanks and colchicine was 161 the positive control ( $1 / 2$ dilutions $800-1.5 \mathrm{nM})$. The results were expressed as the dose 162 that inhibits $50 \%$ growth after the incubation period $\left(\mathrm{IC}_{50}\right)$, estimating the values from a 163 log 10 plot of compound concentration against percentage of viable cells. Data were 164 processed using SigmaPlot 13.0. Micrographs were obtained using an AxioCam ERc5s digital camera in a phase-contrast inverted microscope Zeiss IM (Hicksville, NY, USA).

\section{RESULTS AND DISCUSSION}

Immobilization of OPEr. Immobilization implies protein fixation to a non-soluble

169 solid support. If the activity of the enzyme resists this process, the immobilized

170 biocatalyst is often more stable than the free enzyme, and can be easily separated from

171 the reaction medium to be reused. ${ }^{23}$ However, there is no rational approach to predict

172 which immobilization method will be best suited to produce a robust biocatalyst for a

173 given application, as it depends on the enzyme, the application and the support. ${ }^{24}$ Since

174 protein's conformation and catalytic properties might change depending on the area

175 implicated in the attachment, we have prepared and tested four versions of OPEr 
176 immobilized on functionalized magnetic nanoparticles, whose characteristics are

177 summarized in Table 1. The immobilization yields were close to $100 \%$ except for AMNP-

178 GA-OPEr (65\%), which could be due to the lower protein load accepted in this

179 preparation and justifies its lower specific activity.

180 SiMAG-Octyl-OPEr is prepared by a quite simple method, in which the hydrophobic

181 regions of the lipase are non-covalently attached to a hydrophobic carrier. The enzyme

182 has few flexibility restrictions, but the catalyst may be lost during catalysis. The other

183 three methods tested involve the formation of covalent linkages causing the irreversible

184 binding of the lipase to the carrier. In each of these cases the protein is attached through

185 different structural regions, depending on the carrier functionalities and on the

186 immobilization conditions. ${ }^{21,25-27}$ In AMNP-GA-OPEr and mCLEAs-OPEr the peptide chain

187 is involved in the linkages, which probably causes protein rigidification. This can be

188 positive to maintain activity and stability ${ }^{25,28}$ but may also hamper the accessibility of

189 bulky substrates to the active center. SiMAG-Octyl-OPEr, mCLEAs-OPEr, and AMNP-GA-

190 OPEr were successfully applied in synthesis of esters of volatile fatty acids by direct

191 esterification, ${ }^{21}$ and other lipases have been immobilized by these procedures on the same or other carriers. ${ }^{27,29-41}$

193 The fourth preparation (AMNP-CH-OPEr) was obtained according to a less

194 conventional strategy, avoiding the implication of the protein moiety of the lipase in its

195 immobilization. Here, the covalent linkage is held between free amino groups of the

196 carrier and aldehydes produced in the glycidic component of OPEr. Schiff's bases are

197 formed via reductive amination, ${ }^{42}$ probably by multiple points, and the oxidized

198 carbohydrate chains act as slightly flexible linkers. This has a positive impact in 
maintaining the enzyme conformation since the protein moiety is not attached in a rigid conformation, there are not additional structural constraints, and the enzyme has more

201 chances to adapt for the entry of large substrates. Nevertheless, this flexibility could make the enzyme more susceptible to inactivation. ${ }^{43}$

Transesterification of $\beta$-sitostanol and methyl oleate. In a former work, Molina-

Gutiérrez et al. ${ }^{4}$ reported that $\beta$-sitostanol is fairly soluble at $25^{\circ} \mathrm{C}$ in methyl oleate even at the highest concentration assayed $(80 \mathrm{mM})$, obtaining esterification yields around $90 \%$ in $2 \mathrm{~h}$ with soluble OPEr in the absence of co-solvents. Thus, this $\beta$-sitostanol concentration and temperature were chosen for the experiments performed in the current work. GC/MS analysis of the commercial substrate indicated that it contained $80 \% \beta$-sitostanol and a second component that was identified as ergostanol based on its

210 mass spectrum. All the biocatalysts tested transesterified both stanols in a similar way,

211 yielding the corresponding oleic esters (Figure 1), which confirmed that the wide

212 substrate specificity of $\mathrm{OPEr}^{17}$ is maintained upon immobilization. Several lipases have 213 been used for ergosterol esterification, ${ }^{5,44,45}$ but we have not found any report on 214 esterification of ergostanol.

215 The results from the esterification and recycling of the catalysts assayed are 216 presented in Figure 2. In the first reaction cycle (Figure 2a, R1), both the free OPEr and 217 SiMAG-Octyl-OPEr produced $86 \%$ and $72 \%$ esters in $15 \mathrm{~h}$, while the other catalysts gave 218 esterification yields between $18 \%$ and $40 \%$. However, an enhanced esterification 219 efficiency was observed in the second (R2) and third (R3) cycles for all of them, with 220 stably high conversions in the fourth (R4) and fifth (R5) cycles. It is interesting to note 221 that in 2 h-reactions catalyzed by SiMAG-Octyl-OPEr and AMNP-CH-OPEr the 
esterification yield determined in cycles R4 and R5 was very close to the maximum values produced in $15 \mathrm{~h}$ in the previous cycles. As commented before, the degree of

224 flexibility of OPEr is expected to be higher in these two preparations, allowing an easier and faster accommodation of the active center. Notably, in the fourth and fifth cycles,

226 the catalytic activity of AMNP-CH-OPEr modestly overpassed that of the catalyst attached by hydrophobicity.

Although we cannot give a conclusive explanation to this behavior, the increase of the activity detected after recycling could be due to not only to the gradual accommodation of the enzyme to the reaction conditions, but also to a beneficial effect of the presence of residual amounts of components from the previous reaction cycle. with the enzymatic synthesis of sterol esters catalyzed by CRL immobilized on different scaffolds. In general, esterification and/or transesterification reactions were carried out in the presence of a co-solvent, at temperature ranges between $35-55^{\circ} \mathrm{C}$ for $6-24 \mathrm{~h} .{ }^{46-}$

${ }^{49}$ The recyclability, if evaluated, varied between a complete activity loss after 5 cycles to nearly full maintenance of the catalytic efficiency after 12 cycles. Several noncovalently immobilized commercial lipases (Novozyme 435, Lipozyme RM IM and Lipozyme TL IM) tested for this application displayed lower efficiency than CRL. ${ }^{50,51}$

Stanol esters are included in foods intended for human consumption, and thus the possible release of toxic compounds from the immobilized biocatalysts to the reaction

242 medium must be discarded before considering the potential biotechnological application of this approach. To do so, we evaluated the effect of supernatants from concentrated suspensions of the biocatalysts on the viability of HeLa and A549 cells. 
245 Untreated cells were used as negative control and colchicine, a drug that depolymerizes

246 microtubules and blocks the mitotic spindle, affecting cellular viability, ${ }^{52}$ as positive 247 control.

248 According to the analysis of $\mathrm{IC}_{50}$ (Table 2 ), none of the extracts produced cytotoxic

249 effects after $48 \mathrm{~h}$ of exposure, while low concentrations of colchicine strongly affected 250 cellular viability.

251 As an example, Figure 3 shows the micrographs of the cells treated with the extract from AMNP-CH-OPEr at the maximum concentration evaluated, together with a positive and a negative control. The images obtained in the other treatments are comparable to these. Hence, microscopic inspection of the cells supported the $\mathrm{IC}_{50}$ results. There are not observable differences between untreated and treated cells, while the micrographs of the colchicine control showed the massive presence of non-adherent cells.

257 Cascade reactions for green and sustainable synthesis of stanol esters using oil wastes

258 as secondary raw materials. The above results proved the suitability of the catalysts to 259 produce stanol esters and confirmed methyl oleate as an excellent solvent and acyl 260 donor. In fact, the renewable, nontoxic, and biodegradable character of fatty acid esters 261 makes them an interesting choice for this and other processes devoted to the synthesis 262 of added-value commodities. ${ }^{53}$ However, the industrial production of FAMEs relies in chemical transesterification that involves the use of toxic and polluting catalysts and

264 reagents, high temperatures, and leaves a hardly recyclable waste. Cleaner biocatalytic manufacturing processes can be implemented for synthesis of FAMEs, but the product must be cost-competitive. Several lipases are able of producing FAMEs, and OPEr has

267 shown to do it sustainably, using triglycerides from cooking oil wastes in a solventless 
reaction medium at ambient temperature. ${ }^{42}$ Thus, in the search of a process compliant

with the principles of green chemistry, we explored the possibility of coupling

270 triglycerides' methanolysis with the synthesis of stanol esters, using the same $\mathrm{OPEr}$

271 biocatalyst in sequential reactions.

Among the four immobilized biocatalysts available, we selected AMNP-CH-OPEr for these cascade reactions because this preparation was the most efficient in the synthesis of FAMEs ${ }^{42}$ and one of the best to synthesize stanol esters, according to the results presented in Figure 2. Indeed, the first reaction of the cascade, consisting in the methanolysis of triglycerides from oil residues, yielded a semi-solid residue of glycerol and a liquid fraction composed of $96.6 \%$ FAMEs, $1 \%$ diglycerides and $2.4 \%$ free fatty acids. Methyl oleate was, by far, the main component, but up to four methyl esters were identified by GC/MS. This liquid fraction was mixed with the stanols without further treatment or purification, and transesterification was catalyzed by the same biocatalyst without adding any other component.

Samples were analyzed after 2 and $15 \mathrm{~h}$ by GC, showing the peaks of the oleic, palmitic, stearic and linoleic stanol esters, and a decrease in the content of FAMEs,

284 diglycerides and free stanols over time (Figure 4a-b). The reaction reached maximum esterification (85\%) after $15 \mathrm{~h}$ in the first cycle, but around $80 \%$ of stanol esters were

286 synthesized in $2 \mathrm{~h}$ from the second cycle onwards (Figure 4c). This observation confirms

287 that, more than loosing activity, this OPEr catalyst gains efficiency when recycled, 288 maintaining esterification yields of $80 \%$ in $2 \mathrm{~h}$ of reaction after five reuses (Figure $4 \mathrm{c}$ ). In 289 addition, the reaction proceeded faster and more efficiently than when commercial 
290 methyl oleate was used as acyl donor, probably due to a positive effect of other

291 components of the FAMEs mixture resulting from the previous enzymatic synthesis.

292 He et al. $^{3}$ reviewed the most recent publications on lipase-catalyzed synthesis of

293 fatty acid esters of phytosterols. Few papers report on the synthesis of these compounds

294 using immobilized enzyme as catalysts and oils or mixtures of FAMEs as acyl donors and,

295 in general, the experimental conditions applied are much less eco-friendly than those

296 used in the current work. For example non-covalently immobilized CRL ${ }^{46}$ produced $74-$

$29796.3 \%$ sterol or stanol esters using cosolvents, and temperatures between $40-55$ ㄷ, but

298 recyclability was not tested. Similarly, a novel approach in which transesterification was

299 performed at $55{ }^{\circ} \mathrm{C}$ in a pickering emulsion stabilized by mesoporous carbon

300 nanospheres with immobilized CRL gave excellent transesterification yields and

301 recyclability. ${ }^{11}$ Transesterification of phytosterols with soybean oil catalyzed by

302 Novozyme $435^{54}$ produced $96 \%$ esters at $85 \stackrel{\circ}{\circ}$ and using $\mathrm{SC}-\mathrm{CO}_{2}$, and the use of

303 Lipozyme TL IM in a packed bed continuous flow reactor operated at 60 ㄷ $\mathrm{C}$ yielded $70 \%$

304 and $57 \%$ phytosterol esters from linseed and fish oil in $n$-hexane, respectively. ${ }^{55}$

305 To summarize, this work has demonstrated that stanol esters can be easily 306 synthetized at room temperature using a single immobilized variant of the lipase OPEr

307 as biocatalyst, and stanols, wasted cooking oil and methanol as substrates. The whole

308 procedure involves a cascade of two consecutive reactions, oil methanolysis and stanols

309 transesterification, and the biocatalyst can be recycled for further reactions without

310 activity loss. These results point to the suitability of this novel strategy to synthetize

311 stanol esters by a green and sustainable procedure from non-expensive wastes as

312 substrates, according to the current concept of circular economy. 


\section{Abbreviations}

314 AMNP: magnetic nanoparticles functionalized with reactive amino groups in their

315 surface

316 AMNPs-GA-OPEr: OPEr covalently immobilized on AMNPs treated with glutaraldehyde

317 to leave reactive aldehyde surface groups

318 AMNPs-CH-OPEr: OPEr covalently immobilized, through aldehyde groups generated by

319 oxidation of its glycidic chains, on AMNPs

320 APTS: 3-aminopropyl)triethoxysilane

321 FAMEs: fatty acid methyl esters

322 GC: gas chromatography

323 GC/MS: gas chromatography/mass spectrometry

324 mCLEAs-OPEr: magnetic cross-linked enzyme aggregates

325 MTT: 3-(4,5-dimethylthiazol-2-yl)-2,5-diphenyltetrazolium bromide

326 pNPB: $p$-nitrophenyl butyrate

327 OPEr: versatile lipase of Ophiostoma piceae

328 SDS: sodium dodecyl sulphate

329 SiMAG-Octyl-OPEr: OPEr non-covalently immobilized by hydrophobic interaction on

330 magnetic nanoparticles with octyl groups in their surface

332 ACKNOWLEDGMENT

333 The authors acknowledge Isabel Barasoaín for her help in designing the cytotoxicity

334 experiments, and Mercedes Sánchez from the Gas Chromatography Facility at CIB, for 
technical help. The authors would also like to thank IBISBA1.0 project (H2020 730976) and the SusPlast-CSIC Interdisciplinary Platform for their support.

Funding

This work was supported by the Spanish projects GLYSUS RTI2018-093683-B-I00 from MICIU/AEI/FEDER, and RETOPROSOST-2-CM S2018/EMT-4459 from Comunidad de Madrid.

\section{REFERENCES}

344 (1) Ostlund, R. Phytosterols, Cholesterol Absorption and Healthy Diets. Lipids 2007, $42(1), 41-45$.

(2) Musa-Veloso, K.; Poon, T. H.; Elliot, J. A.; Chung, C. A Comparison of the LDL-

(3) He, W.-S.; Zhu, H.; Chen, Z.-Y. Plant Sterols: Chemical and Enzymatic Structural Modifications and Effects on Their Cholesterol-Lowering Activity. J. Agric. Food

(4) Molina-Gutiérrez, M.; Hakalin, N. L. S.; Rodríguez-Sanchez, L.; Prieto, A.; Martínez, M. J. Green Synthesis of $\beta$-Sitostanol Esters Catalyzed by the Versatile Lipase/Sterol Esterase from Ophiostoma piceae. Food Chem. 2017, 221, 14581465.

357 (5) He, W. Sen; Li, L.; Zhao, J.; Xu, H.; Rui, J.; Cui, D.; Li, H.; Zhang, H.; Liu, X. Candida 
Sp. 99-125 Lipase-Catalyzed Synthesis of Ergosterol Linolenate and Its Characterization. Food Chem. 2019, 280, 286-293.

360 (6) Negishi, S.; Hidaka, I.; Takahashi, I.; Kunita, S. Transesterification of Phytosterol and Edible Oil by Lipase Powder at High Temperature. JAOCS, J. Am. Oil Chem. Soc. $2003,80(9), 905-907$.

363

(7) Torrelo, G.; Torres, C. F.; Reglero, G. Enzymatic Strategies for Solvent-Free Technol. 2012, 114 (6), 670-676.

366

(8) Villeneuve, P.; Turon, F.; Caro, Y.; Escoffier, R.; Baréa, B.; Barouh, B.; Lago, R.; Piombo, G.; Pina, M. Lipase-Catalyzed Synthesis of Canola Phytosterols Oleate Esters as Cholesterol Lowering Agents. Enzyme Microb. Technol. 2005, 37 (1), 150-155.

370

(9) Vu, P.-L.; Shin, J.-A.; Lim, C.-H.; Lee, K.-T. Lipase-Catalyzed Production of 2004, $37(2), 175-180$.

(10) Weber, N.; Weitkamp, P.; Mukherjee, K. D. Steryl and Stanyl Esters of Fatty Acids by Solvent-Free Esterification and Transesterification in Vacuo Using Lipases from Rhizomucor miehei, Candida antarctica, and Carica papaya. J. Agric. Food Chem. 2001, 49 (11), 5210-5216.

(11) Dong, Z.; Liu, Z.; Shi, J.; Tang, H.; Xiang, X.; Huang, F.; Zheng, M. Carbon Nanoparticle-Stabilized Pickering Emulsion as a Sustainable and HighPerformance Interfacial Catalysis Platform for Enzymatic Esterification/Transesterification. ACS Sustain. Chem. Eng. 2019, 7 (8), 7619- 
(12) Xiao, Y.; Zheng, M.; Liu, Z.; Shi, J.; Huang, F.; Luo, X. Constructing a Continuous Flow Bioreactor Based on a Hierarchically Porous Cellulose Monolith for Ultrafast and Nonstop Enzymatic Esterification/Transesterification. ACS Sustain. Chem. Eng. 2019, 7 (2), 2056-2063.

(13) Sheldon, R. A.; van Pelt, S. Enzyme Immobilisation in Biocatalysis: Why, What and How. Chem. Soc. Rev. 2013, 42 (15), 6223-6235.

(14) Ansorge-Schumacher, M. B.; Thum, O. Immobilised Lipases in the Cosmetics Industry. Chem. Soc. Rev. 2013, 42 (15), 6475-6490.

(15) Turcheniuk, K.; Tarasevych, A.; Kukhar, V.; Boukherroub, R.; Szunerits, S. Recent

(16) Xu, J.; Sun, J.; Wang, Y.; Sheng, J.; Wang, F.; Sun, M. Application of Iron Magnetic Nanoparticles in Protein Immobilization. Molecules 2014, 19 (8), 11465-11486.

(17) Barriuso, J.; Vaquero, M. E.; Prieto, A.; Martínez, M. J. Structural Traits and Sterol Esterases and Lipases as Catalysts. BMC Genomics 2013, 14 (1). 
of Three Novel Fungal Lipases/Sterol Esterases Predicted in Silico: Comparison with Other Enzymes of the Candida rugosa-like Family. Appl. Microbiol. Biotechnol. 2015, 99 (23), 10057-10067.

407

408

(21) Molina-Gutiérrez, M.; Hakalin, N.; Rodríguez-Sánchez, L.; Alcaraz, L.; López, F.; Martínez, M.; Prieto, A. Effect of the Immobilization Strategy on the Efficiency and Recyclability of the Versatile Lipase from Ophiostoma piceae. Molecules 2019, 24 (7), 1313.

(22) Mosmann, T. Rapid Colorimetric Assay for Cellular Growth and Survival: Application to Proliferation and Cytotoxicity Assays. J. Immunol. Methods 1983, $65(1-2), 55-63$.

(23) Shuai, W.; Das, R. K.; Naghdi, M.; Brar, S. K.; Verma, M. A Review on the Important Aspects of Lipase Immobilization on Nanomaterials. Biotechnol. Appl. Biochem. 2017, 64 (4), 496-508.

(24) Cao, L. Carrier-bound Immobilized Enzymes. Principles, Applications and Design; Wiley-VCH: Weinheim, Germany, 2005.

(25) Barbosa, O.; Ortiz, C.; Berenguer-Murcia, Á.; Torres, R.; Rodrigues, R. C.; Fernandez-Lafuente, R. Glutaraldehyde in Bio-Catalysts Design: A Useful Crosslinker and a Versatile Tool in Enzyme Immobilization. RSC Adv. 2014, 4 (4), $1583-1600$.

(26) Betancor, L.; López-Gallego, F.; Hidalgo, A.; Alonso-Morales, N.; Mateo, G. D.-O. C.; Fernández-Lafuente, R.; Guisán, J. M. Different Mechanisms of Protein Immobilization on Glutaraldehyde Activated Supports: Effect of Support Activation and Immobilization Conditions. Enzyme Microb. Technol. 2006, 39 (4), 
428

429

430

431

432

433

434

435

436

437

438

439

440

441

442

443

444

445

446

447

448

449

(27) Kim, M.; Park, J. M.; Um, H. J.; Lee, D. H.; Lee, K. H.; Kobayashi, F.; Iwasaka, Y.; Hong, C. S.; Min, J.; Kim, Y. H. Immobilization of Cross-Linked Lipase Aggregates onto Magnetic Beads for Enzymatic Degradation of Polycaprolactone. J. Basic Microbiol. 2010, 50 (3), 218-226.

(28) Zhang, Y.; Ge, J.; Liu, Z. Enhanced Activity of Immobilized or Chemically Modified Enzymes. ACS Catal. 2015, 5 (8), 4503-4513.

(29) Cruz-Izquierdo, Á.; Picó, E. A.; López, C.; Serra, J. L.; Llama, M. J. Magnetic CrossLinked Enzyme Aggregates (MCLEAs) of Candida antarctica Lipase: An Efficient and Stable Biocatalyst for Biodiesel Synthesis. PLoS One 2014, 9 (12), e115202.

(30) Barbosa, O.; Torres, R.; Ortiz, C.; Fernandez-Lafuente, R. Versatility of Glutaraldehyde to Immobilize Lipases: Effect of the Immobilization Protocol on the Properties of Lipase B from Candida Antarctica. Process Biochem. 2012, 47 (8), 1220-1227.

(31) Cui, Y.; Li, Y.; Yang, Y.; Liu, X.; Lei, L.; Zhou, L.; Pan, F. Facile Synthesis of AminoSilane Modified Superparamagnetic Fe3O4 Nanoparticles and Application for Lipase Immobilization. J. Biotechnol. 2010, 150 (1), 171-174.

(32) Rodrigues De Melo, R.; Alnoch, R. C.; Ferreira Lopes Vilela, A.; Maltempi De Souza, E.; Krieger, N.; Ruller, R.; Sato, H. H.; Mateo, C. New Heterofunctional Supports Based on Glutaraldehyde-Activation: A Tool for Enzyme Immobilization at Neutral PH. Molecules 2017, 22 (7).

(33) Xie, W.; Ma, N. Immobilized Lipase on Fe304 Nanoparticles as Biocatalyst for Biodiesel Production. Energy \& Fuels 2009, 23 (3), 1347-1353. 
(34) Netto, C. G. C. M.; Toma, H. E.; Andrade, L. H. Superparamagnetic Nanoparticles as Versatile Carriers and Supporting Materials for Enzymes. Journal of Molecular Catalysis B: Enzymatic. Elsevier January 2013, pp 71-92.

(35) Liu, Y.; Guo, C.; Liu, C.-Z. Novel Magnetic Cross-Linked Lipase Aggregates for Improving the Resolution of (R, S)-2-Octanol. Chirality 2015, 27 (3), 199-204.

(36) Gricajeva, A.; Kazlauskas, S.; Kalèdienè, L.; Bendikienè, V. Analysis of Aspergillus Sp. Lipase Immobilization for the Application in Organic Synthesis. Int. J. Biol. Macromol. 2018, 108, 1165-1175.

(37) Arana-Peña, S.; Lokha, Y.; Fernández-Lafuente, R. Immobilization on OctylAgarose Beads and Some Catalytic Features of Commercial Preparations of Lipase a from Candida antarctica (Novocor ADL): Comparison with Immobilized Lipase B from Candida antarctica. Biotechnol. Prog. 2019, 35 (1).

(38) Fernandez-Lopez, L.; Pedrero, S. G.; Lopez-Carrobles, N.; Gorines, B. C.; VirgenOrtíz, J. J.; Fernandez-Lafuente, R. Effect of Protein Load on Stability of Immobilized Enzymes. Enzyme Microb. Technol. 2017, 98, 18-25.

(39) Rodrigues, R. C.; Virgen-Ortíz, J. J.; dos Santos, J. C. S.; Berenguer-Murcia, Á.; Alcantara, A. R.; Barbosa, O.; Ortiz, C.; Fernandez-Lafuente, R. Immobilization of Lipases on Hydrophobic Supports: Immobilization Mechanism, Advantages,

(40) Tacias-Pascacio, V. G.; Virgen-Ortíz, J. J.; Jiménez-Pérez, M.; Yates, M.; Torrestiana-Sanchez, B.; Rosales-Quintero, A.; Fernandez-Lafuente, R. Evaluation of Different Lipase Biocatalysts in the Production of Biodiesel from Used Cooking 
Oil: Critical Role of the Immobilization Support. Fuel 2017, 200, 1-10.

(41) Zaak, H.; Siar, E. H.; Kornecki, J. F.; Fernandez-Lopez, L.; Pedrero, S. G.; VirgenOrtíz, J. J.; Fernandez-Lafuente, R. Effect of Immobilization Rate and Enzyme Crowding on Enzyme Stability under Different Conditions. The Case of Lipase from Thermomyces Lanuginosus Immobilized on Octyl Agarose Beads. Process Biochem. 2017, 56, 117-123.

(42) Prieto, A. M.; Molina-Gutiérrez, M.; Martínez, Á. T.; Martínez, M. J. Synthesis of Biodiesel Catalysed by an Enzymatic Crude Immobilised on Magnetic Particles, 2018.

(43) Knezevic, Z.; Milosavic, N.; Bezbradica, D.; Jakovljevic, Z.; Prodanovic, R. Immobilization of Lipase from Candida Rugosa on Eupergit ${ }^{\circledR}$ C Supports by Covalent Attachment. Biochem. Eng. J. 2006, 30 (3), 269-278.

(44) Chaibakhsh, N.; Basri, M.; Rahman, M. B. A.; Adnani, A.; Salleh, A. B. LipaseCatalyzed Synthesis of Ergosterol Ester. Biocatal. Agric. Biotechnol. 2012, 1 (1), $51-56$.

(45) Hammann, S.; Lehnert, K.; Vetter, W. Esterified Sterols and Their Contribution to the Total Sterols in Edible Mushrooms. J. Food Compos. Anal. 2016, 54, 48-54.

(46) Zheng, M.-M.; Dong, L.; Lu, Y.; Guo, P.-M.; Deng, Q.-C.; Li, W.-L.; Feng, Y.-Q.; Huang, F.-H. Immobilization of Candida rugosa Lipase on Magnetic Poly(Allyl Glycidyl Ether-Co-Ethylene Glycol Dimethacrylate) Polymer Microsphere for Synthesis of Phytosterol Esters of Unsaturated Fatty Acids. J. Mol. Catal. B Enzym. 2012, $74(1-2), 16-23$.

(47) Zheng, M.-M.; Lu, Y.; Huang, F.-H.; Wang, L.; Guo, P.-M.; Feng, Y.-Q.; Deng, Q.-C. 
Lipase Immobilization on Hyper-Cross-Linked Polymer-Coated Silica for Biocatalytic Synthesis of Phytosterol Esters with Controllable Fatty Acid Composition. J. Agric. Food Chem. 2013, 61 (1), 231-237.

(48) Zheng, M. M.; Lu, Y.; Dong, L.; Guo, P. M.; Deng, Q. C.; Li, W. L.; Feng, Y. Q.; Huang,

F. H. Immobilization of Candida rugosa Lipase on Hydrophobic/Strong CationExchange Functional Silica Particles for Biocatalytic Synthesis of Phytosterol

(49) Shang, C. Y.; Li, W. X.; Zhang, R. F. Immobilization of Candida rugosa Lipase on ZnO Nanowires/Macroporous Silica Composites for Biocatalytic Synthesis of Phytosterol Esters. Mater. Res. Bull. 2015, 68, 336-342.

(50) He, W.-S.; Cui, D.-D.; Zhang, Y.-L.; Liu, Y.; Yin, J.; Chen, G.; Jia, C.-S.; Feng, B. Highly Efficient Synthesis of Phytosterol Linolenate Catalyzed by Candida rugosa Lipase

(52) Buey, R. M.; Barasoain, I.; Jackson, E.; Meyer, A.; Giannakakou, P.; Paterson, I.; Mooberry, S.; Andreu, J. M.; Díaz, J. F. Microtubule Interactions with Chemically

(51) Miao, M.; Liu, H.; Jiang, B.; Yang, C.; Xia, X.; Zhang, T. Enzyme-Catalysed Synthesis of Plant Steryl Laurate in Non-Aqueous Media Using Salt Hydrate Pairs and Its Characterisation. J. Funct. Foods 2014, 7 (0), 452-461. Predicts Cytotoxicity. Chem. Biol. 2005, 12 (12), 1269-1279.

(53) Lee, S.; Yuk, J. S.; Park, H.; Kim, Y. W.; Shin, J. Multiblock Thermoplastic Elastomers Derived from Biodiesel, Poly(Propylene Glycol), and I -Lactide. ACS Sustain. Chem. Eng. 2017, 5 (9), 8148-8160. 
519 (54) Hu, L.; Llibin, S.; Li, J.; Qi, L.; Zhang, X.; Yu, D.; Walid, E.; Jiang, L. Lipase-Catalyzed Transesterification of Soybean Oil and Phytosterol in Supercritical $\mathrm{CO}_{2}$. Bioprocess Biosyst. Eng. 2015, 38 (12), 2343-2347.

522 (55) Sengupta, A.; Pal, M.; Silroy, S.; Ghosh, M. Comparative Study of Sterol Ester 523 Synthesis Using Thermomyces lanuginosus Lipase in Stirred Tank and Packed-Bed Bioreactors. JAOCS, J. Am. Oil Chem. Soc. 2010, 87 (9), 1019-1025.

525

526 
528 Figure 1 . Scheme of the reaction of transesterification of $80 \mathrm{mM} \beta$-sitostanol and methyl

529 oleate catalyzed by immobilized OPEr. Methyl oleate acts as solvent and as donor of

530 oleic acid. Once completed the reaction, the catalyst is retained in the reaction vessel in

531 seconds, with the help of a Nd magnet. The reaction mixture can be recovered, free of

532 protein, for further purification of the products. The GC chromatograms of samples

533 analyzed at $0 \mathrm{~h}$ and $15 \mathrm{~h}$ are shown at the bottom of the figure. The signal has been

534 magnified from minute 8.5 onwards $(\times 10)$ to improve visualization of the peaks of free

535 stanols an stanol esters.

536 Figure 2. a) Esterification yields of free OPEr (only one reaction cycle) and the OPEr-

537 nanobiocatalysts, and recyclability of the immobilized enzyme in the solventless

538 transesterification of $80 \mathrm{mM}$ of stanols with commercial methyl oleate (99\%). Reactions

539 were performed at $25{ }^{\circ} \mathrm{C}$ for $15 \mathrm{~h}$. b) Detail of the transesterification yields of the four

540 nanobiocatalysts after $2 \mathrm{~h}$ of reaction in the fourth and fifth cycles. R1-R5: reaction

$541 \quad$ cycles 1 to 5.

542 Figure 3. Micrographs of control and treated HeLa and A549 cells after $48 \mathrm{~h}$ incubation.

543 Left: cells treated with colchicine at the maximum concentration assayed. Middle:

544 untreated cells. Right: cells treated with the maximum concentration of AMNP-CH-OPEr

545 extract.

546 Figure 4. Synthesis of stanol esters catalyzed by AMNP-CH-OPEr in a two-step cascade

547 reaction. GC chromatograms of the transesterification of FAMEs and stanols in samples

548 taken at: a) $0 \mathrm{~h}$, and b) $15 \mathrm{~h}$. In both chromatograms, the signal has been magnified ( $\mathrm{x} 5$ ) 
549 from minute 7 onwards to improve visualization of the peaks of free stanols and stanol

550 esters. c) Recycling of the catalyst: \% of stanol esters produced in $2 \mathrm{~h}$ of

551 transesterification across five successive reaction cycles. R1-R5: reaction cycles 1 to 5.

552

553 
Table 1. Summary of the procedures used for OPEr immobilization.

\begin{tabular}{clcc}
\hline Immobilization & Catalyst & $\begin{array}{c}\text { Immob. } \\
\text { yield (\%) }\end{array}$ & $\begin{array}{c}\text { Specific activity }^{\mathrm{b}} \\
\text { (mU/mg carrier) }^{\text {(m) }}\end{array}$ \\
\hline Hydrophobicity & SiMAG-Octyl- & $99 \pm 1$ & $843 \pm 69$ \\
OPEr & AMNP-GA-OPEr & $65 \pm 8$ & $334 \pm 5$ \\
Covalent & mCLEAS-OPEr & $99 \pm 2$ & $769 \pm 58$ \\
& AMNP-CH-OPEr & $96 \pm 3$ & $709 \pm 19$ \\
\hline
\end{tabular}

556 ammob. yield (\%) = (immobilized activity/starting activity) $\times 100$

557 bThe specific activity of the different preparations with the versatile lipase attached to

558 magnetic nanoparticles was determined using $p$ NPB as substrate.

559 
560 Table 2. IC50 values of nanobiocatalysts extract and colchicine as standard control.

\begin{tabular}{lccc}
\hline Extract/compound & $\begin{array}{c}\text { IC50 } \\
\text { HeLa }\end{array}$ & $\begin{array}{c}\text { IC50 } \\
\text { A549 }\end{array}$ & $\begin{array}{c}\text { [Biocatalyst] } \\
\text { in the reactions }\end{array}$ \\
\hline Colchicine $^{\mathrm{a}}$ & $63.2 \pm 9.4 \mathrm{nM}$ & $93.0 \pm 5.7 \mathrm{nM}$ & -- \\
AMNPs-CH-OPEr & $>140 \mathrm{mg} / \mathrm{mL}$ & $>140 \mathrm{mg} / \mathrm{mL}$ & $76 \mathrm{mg} / \mathrm{mL}$ \\
AMNPs-GA-OPEr & $>250 \mathrm{mg} / \mathrm{mL}$ & $>250 \mathrm{mg} / \mathrm{mL}$ & $204 \mathrm{mg} / \mathrm{mL}$ \\
SiMAG-Octyl-OPEr & $>140 \mathrm{mg} / \mathrm{mL}$ & $>140 \mathrm{mg} / \mathrm{mL}$ & $84 \mathrm{mg} / \mathrm{mL}$ \\
mCLEAs-OPEr & $>140 \mathrm{mg} / \mathrm{mL}$ & $>140 \mathrm{mg} / \mathrm{mL}$ & $96 \mathrm{mg} / \mathrm{mL}$ \\
\hline
\end{tabular}

561

apositive control

562 


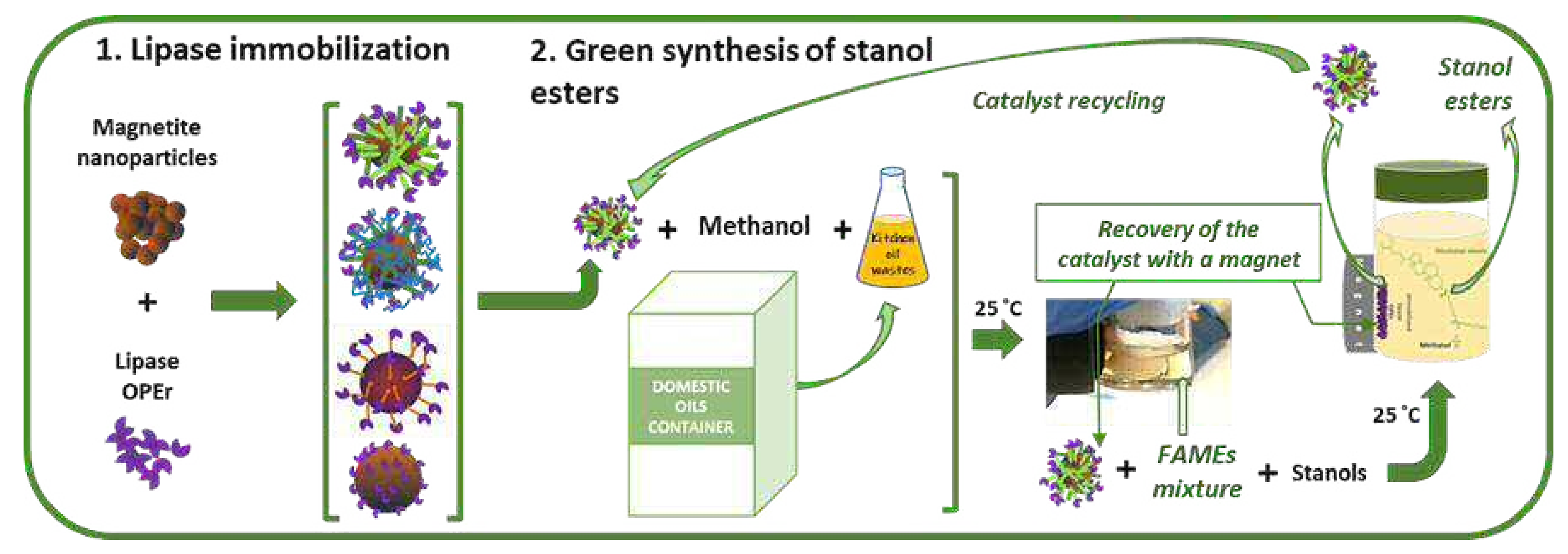




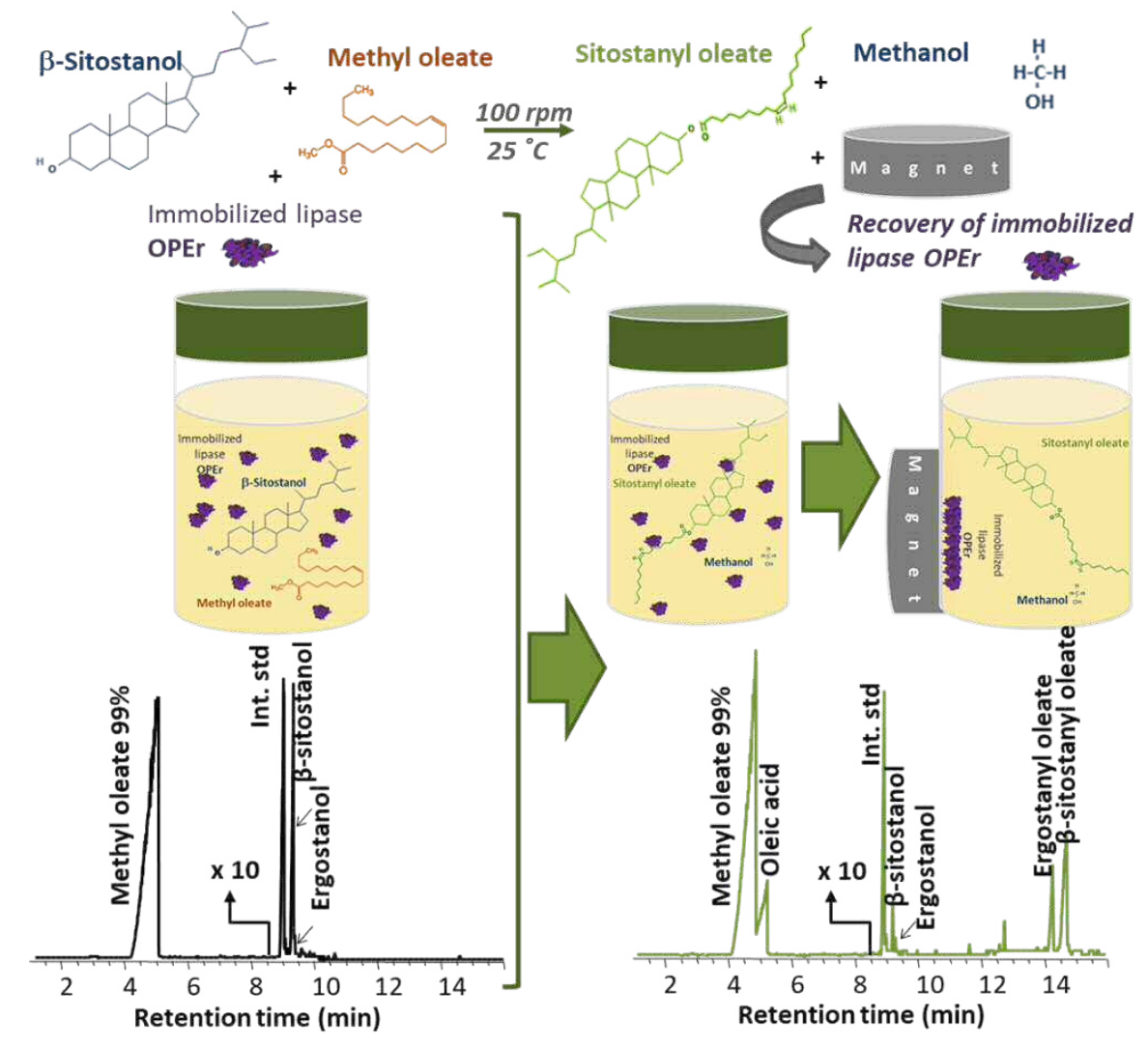

$564 \quad$ Fig. 1 

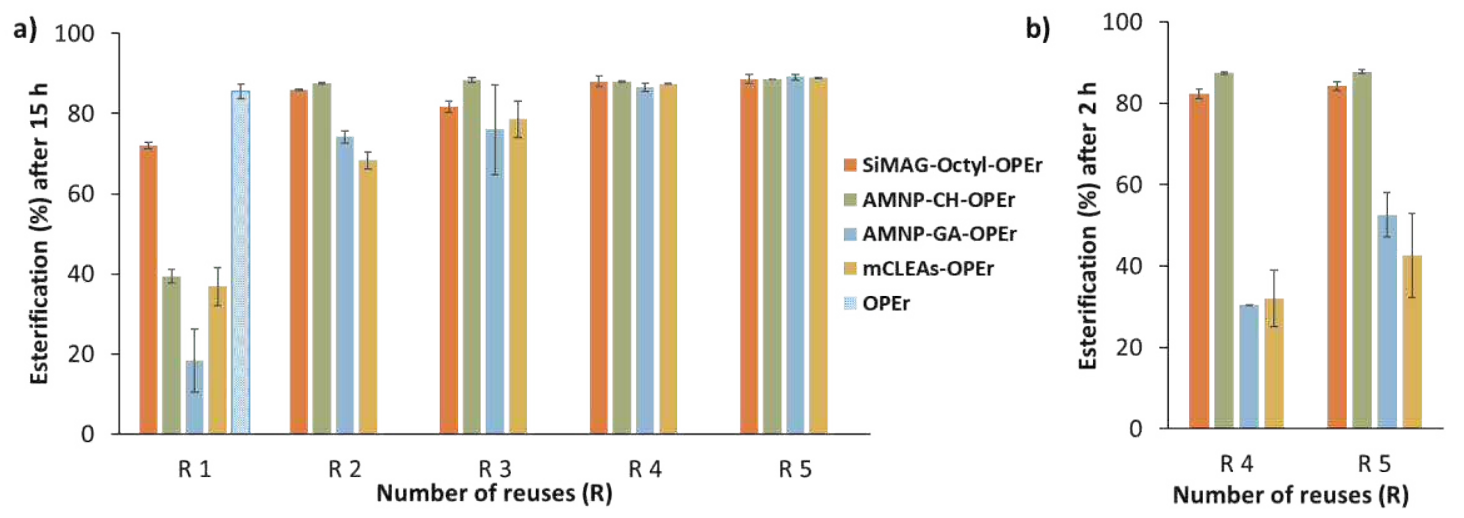

567

$568 \quad$ Fig. 2

569 
571

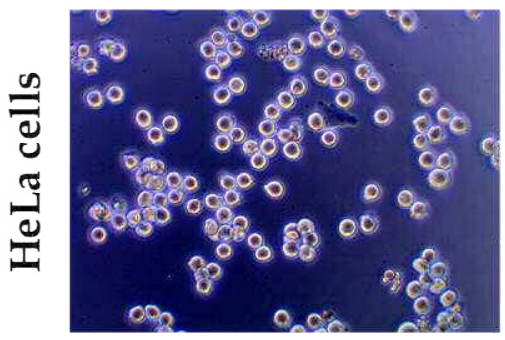

Colchicine

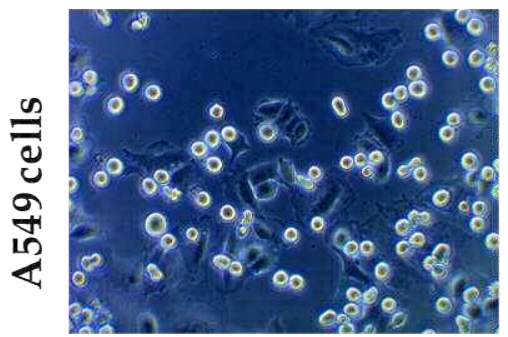

572

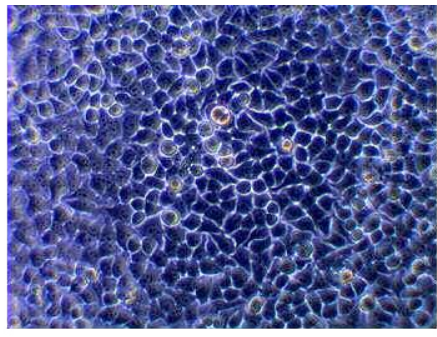

Control

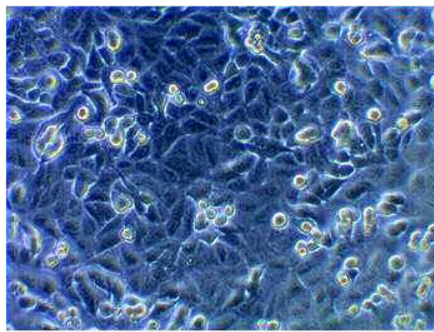

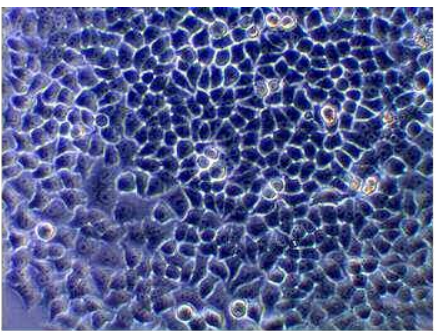

Nanobiocatalysts

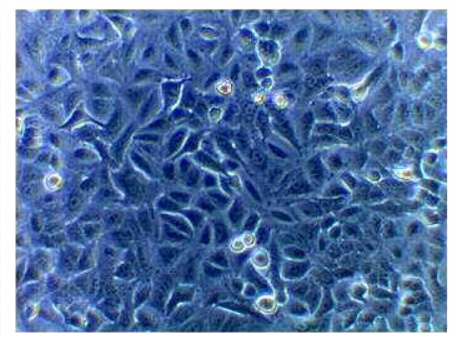

$573 \quad$ Fig. 3

574 
a)

b)

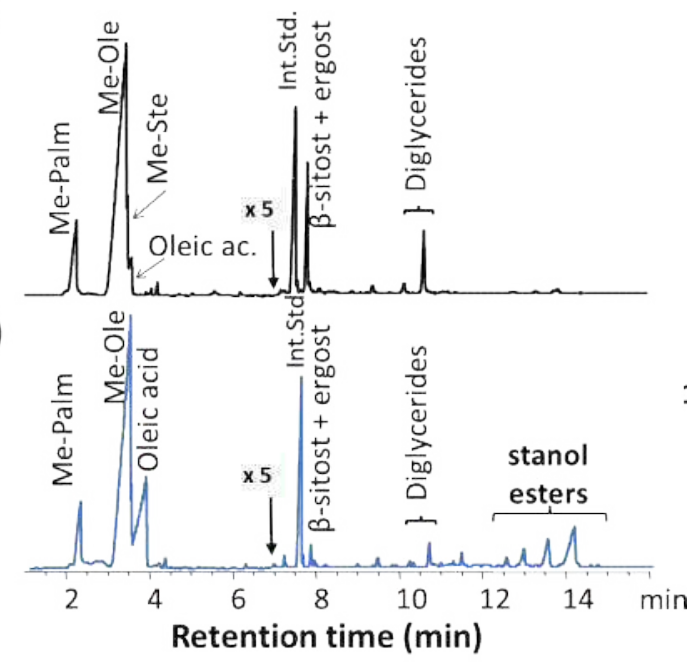

c)

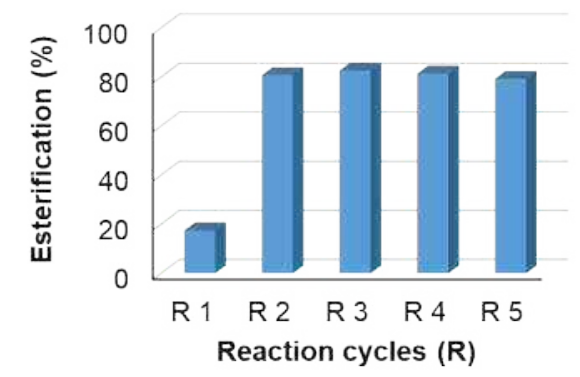

$577 \quad$ Fig. 4 